\title{
BLOOD VOLUME AND HAEMATOCRIT STUDIES IN RESPIRATORY DISTRESS SYNDROME OF THE NEWBORN
}

\author{
BY
J. A. INALL, M. M. BLUHM* MARGARET M. KERR, T. A. DOUGLAS, C. S. HOPE, and J. H. HUTCHISON
From the Departments of Child Health and Biochemistry, University of Glasgow

(RECEIVED FOR PUBLICATION FEBRUARY 18, 1965)

The observation that a raised venous pressure appears to be of benefit to newborn babies with respiratory distress (Bonham Carter, Bound, and Smellie, 1956) led Bound, Harvey, and Bagshaw (1962) to assess the effect of delayed clamping of the umbilical cord of premature babies. In that investigation it was concluded that the placental transfusion was responsible for the lower incidence of respiratory distress in those premature babies where clamping of the cord was delayed. It occurred to us that these observations might have a common basis in some abnormality of the blood volume in those babies who develop the respiratory distress syndrome (RDS). While we were studying a therapeutic approach to RDS (Hutchison, Kerr, Douglas, Inall, and Crosbie, 1964), we took the opportunity to measure the blood volumes of 17 babies. A group of 20 normal premature babies was also studied by the same technique. This paper describes the results of these studies.

The criteria previously described for the diagnosis of severe idiopathic respiratory distress (Hutchison et al., 1964) were common to all cases. These were (1) respiratory grunting; (2) tachypnoea over 60 per minute after the first hour; (3) marked and persistent sternal, subcostal, and intercostal recession during inspiration; (4) cyanosis when breathing air; and (5) characteristic radiographic changes, i.e. diffuse reticulogranular mottling in the lung fields and an 'air bronchogram'.

\section{Material and Methods}

The blood volumes were measured at times varying from $2 \frac{1}{2}$ to 9 hours after birth. 13 of the 17 babies with RDS had birth weights below $2.5 \mathrm{~kg}$. The 20 'normal' babies were healthy newborns with a birth weight of less than $2.5 \mathrm{~kg}$. In 16 the blood volumes were measured

* Present address: Radiotherapy Department, North Middlesex Hospital, Silver Street, Edmonton, London N.18. within 9 hours of birth. Although the time of cord clamping was not accurately recorded, the policy in the hospital was such that few, if any, of the babies that were studied would have had the cord clamping delayed.

Haematocrits.-These were determined in a microhaematocrit centrifuge (Hawksley Ltd., London).

Blood volumes were estimated by an isotope dilution technique using ${ }^{131}$ I radioiodinated human serum albumin (RIHSA) obtained from Radiochemical Centre, Amersham, England. The radioactivity was measured in a scintillation counter (Isotope Developments Ltd.). 30 minutes before the injection of the radioiodinated albumin, $1 \mathrm{mg}$. potassium iodide was given intravenously to minimize the possible uptake of ${ }^{131} \mathrm{I}$ by the thyroid gland.

Preparation of RIHSA for Injection.-The RIHSA was diluted with sterile water so that the final solution contained $0.5 \mu \mathrm{c}^{131} \mathrm{I} / \mathrm{ml}$.; $1 \%$ stable HSA was added as carrier.

Measurement of Quantity Injected.-The quantity administered was determined by counting the syringe before and after the injection. For this purpose, the syringe was placed into a plastic adapter, thus achieving a constant spatial relation between radioactivity and detector (Fig. 1).

Since the blood samples were diluted to $3 \mathrm{ml}$. with water and counted in a plastic vial, it was necessary to derive the factor relating the activity of $1 \mathrm{ml}$. RISHA in the syringe adapter to $1 \mathrm{ml}$. diluted to $3 \mathrm{ml}$. and counted in a plastic vial. This factor was determined experimentally and used throughout the investigation.

Technique of Injection and Sampling.-The RIHSA was injected into a scalp vein through a polythene catheter attached to a needle. After completion of the injection the syringe was refilled through a three-way tap with $20 \%$ fructose solution and this also was injected through the catheter and needle. Blood samples were taken from an umbilical catheter 5,15 , and 30 minutes after the initial injection.

Haematocrits were measured on each sample in 
duplicate, and for radioactivity $1 \mathrm{ml}$. of whole blood was diluted with $2 \mathrm{ml}$. water and counted in a plastic vial in the scintillation counter. A semilogarithmic plot of activity against time enabled the zero time activity to be determined by extrapolation.

The whole blood volume was obtained by dividing the counts injected by the activity of the zero time sample:

i.e. $\frac{\text { Actual counts } / 100 \mathrm{sec} \text {. injected }}{\text { Counts } / \mathrm{ml} \text {. whole blood } / 100 \mathrm{sec}}=$ Whole blood

In certain cases plasma was prepared and this was counted instead of the whole blood. However, this procedure requires the removal of a greater volume of blood from the baby and for this reason whole blood was preferred. It should be stated that RIHSA measures plasma volume directly, the red cell volume and total blood volume being inferred on the assumption that the packed cell volume of the blood sample is the same as the whole body haematocrit. We know, of course, that this is not so in adults, but correction factors for premature infants of different weights and gestation periods are not available. We do not think that our assumption invalidates our subsequent arguments.

\section{Results}

The data for the normal babies are shown in Table 1 and for the babies with RDS in Table 2 . It will be seen that the mean value for the blood volume of the normal babies was $107 \mathrm{ml} / \mathrm{kg}$., and $94 \mathrm{ml} . / \mathrm{kg}$. for the babies with RDS, but the difference is not statistically significant $(p>0 \cdot 1)$. The results of the haematocrit estimations show a mean figure of $58 \%$ for the normal babies and $48 \%$ for the babies with RDS, and this is statistically a highly significant difference $(p<0 \cdot 01)$.

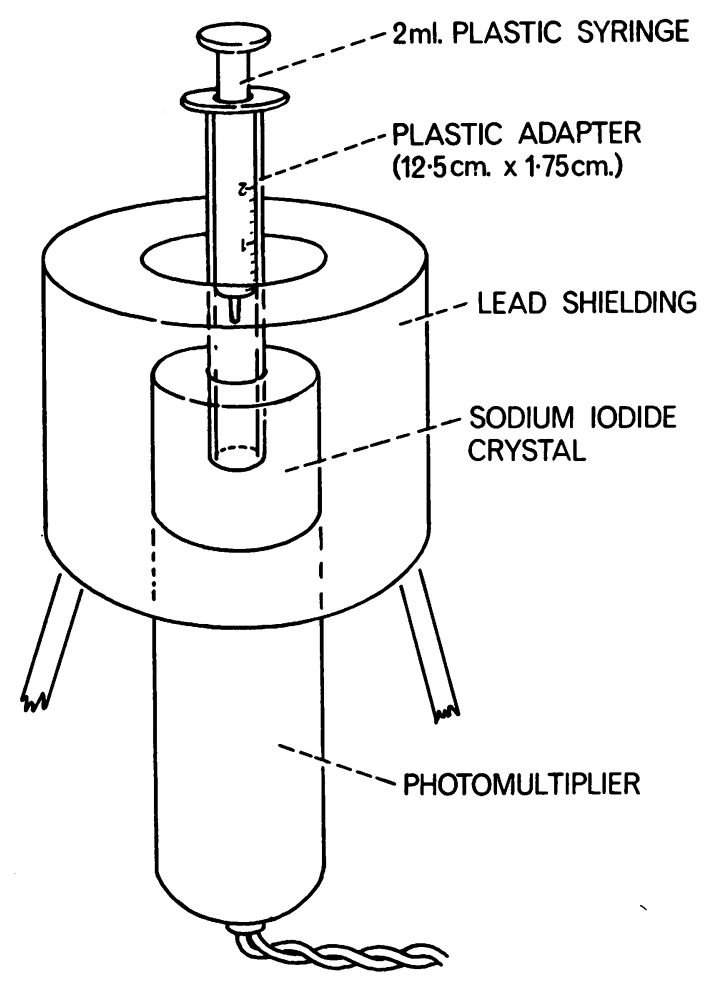

FIG.-Illustration of plastic syringe and adapter in IDL scintillation counter.

TABLE 1

DETAILS OF NORMAL BABIES

\begin{tabular}{|c|c|c|c|c|c|c|c|}
\hline \multicolumn{3}{|c|}{ Case No. } & Weight (kg.) & $\underset{\text { (hr. } \text { min.) }}{\text { Age }}$ & Blood Volume (ml.) & $\begin{array}{c}\text { Blood Volume } \\
\text { (ml./kg.) }\end{array}$ & Haematocrit (\%) \\
\hline & $\begin{array}{r}1 \\
2 \\
3 \\
4 \\
5 \\
6 \\
7 \\
8 \\
9 \\
10 \\
11 \\
12 \\
13 \\
14 \\
15 \\
16 \\
17 \\
18 \\
19 \\
20\end{array}$ & & $\begin{array}{l}2.29 \\
1.78 \\
1.97 \\
1.18 \\
2.23 \\
1.41 \\
1.76 \\
2.15 \\
1.94 \\
2.02 \\
2.38 \\
1.55 \\
2.08 \\
1.98 \\
2.33 \\
1.84 \\
2.05 \\
1.76 \\
1.73 \\
1.63\end{array}$ & 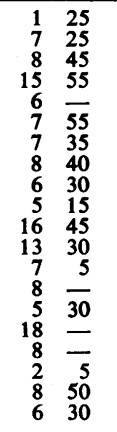 & $\begin{array}{l}224 \\
188 \\
175 \\
206 \\
198 \\
145 \\
227 \\
294 \\
216 \\
230 \\
245 \\
142 \\
266 \\
272 \\
235 \\
227 \\
196 \\
186 \\
172 \\
102\end{array}$ & $\begin{array}{r}97.7 \\
105.5 \\
88.7 \\
115.6 \\
88.7 \\
102.8 \\
128.9 \\
136.7 \\
111.2 \\
113.9 \\
102.9 \\
91.6 \\
127.7 \\
137.4 \\
100.8 \\
123.3 \\
95.5 \\
105.6 \\
99.4 \\
62.5\end{array}$ & $\begin{array}{l}63 \\
65 \\
50 \\
74 \\
50 \\
63 \\
63 \\
53 \\
62 \\
68 \\
56 \\
45 \\
42 \\
64 \\
48 \\
59 \\
49 \\
61 \\
61 \\
66\end{array}$ \\
\hline $\begin{array}{l}\text { Mean } \\
\text { SD } \\
\text { SEM }\end{array}$ & $\begin{array}{ll}\cdots & \\
\cdots & \cdots \\
\cdots & \end{array}$ & $\begin{array}{l}\cdots \\
\cdots \\
.\end{array}$ & $\begin{array}{l}1.93 \\
0.259 \\
0.059\end{array}$ & & $\begin{array}{l}207 \cdot 3 \\
45 \cdot 58 \\
10 \cdot 46\end{array}$ & $\begin{array}{c}106 \cdot 8 \\
17 \cdot 87 \\
4 \cdot 09\end{array}$ & $\begin{array}{c}58 \cdot 1 \\
8 \cdot 30 \\
1 \cdot 90\end{array}$ \\
\hline
\end{tabular}


TABLE 2

DETAILS OF BABIES WITH RESPIRATORY DISTRESS SYNDROME

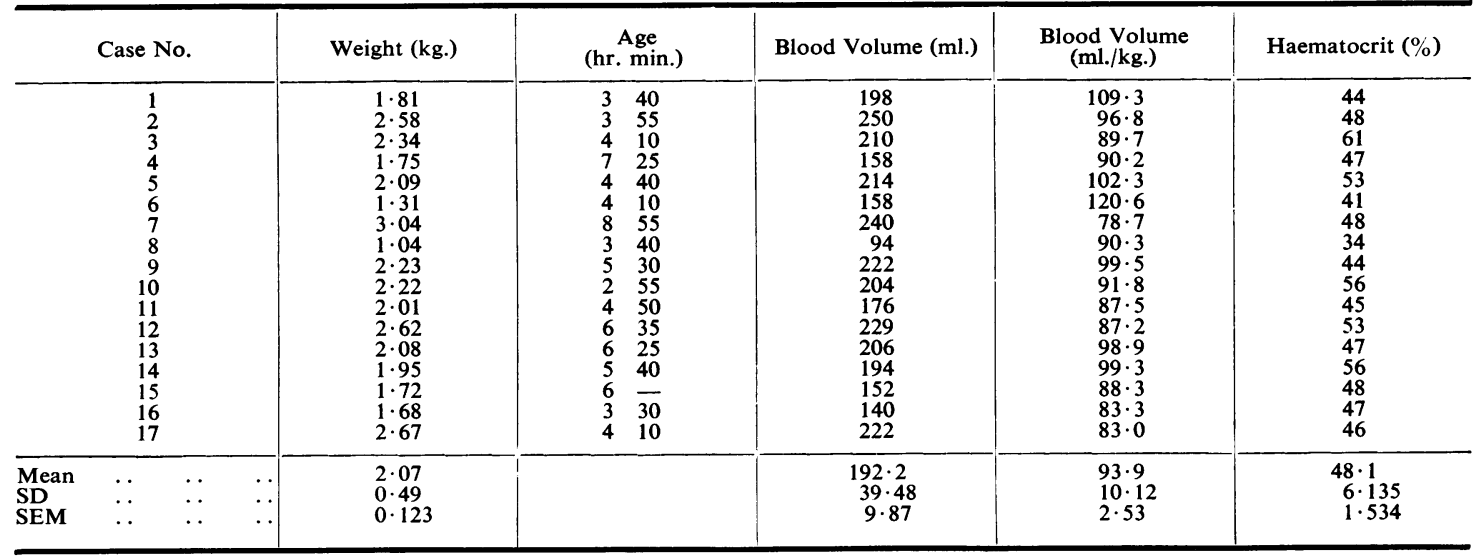

\section{Discussion}

Assessment of the blood volume, its alterations in the immediate postnatal period, and the factors involved in such alterations in the normal newborn have been made by a number of workers. Some have also made conjectures as to the relation of such changes to the development of RDS. These alterations in blood volume could be of clinical importance if delayed clamping of the umbilical cord, which results in a placental transfusion, can prevent the development of RDS (Bound et al., 1962).

The various studies of the blood volume of the newborn infant have produced somewhat conflicting results. Gairdner, Marks, Roscoe, and Brettell (1958) and Clark and Gairdner (1960) have suggested that there is a diminution in the blood volume in the first 2 hours of life due to an outward shift of plasma fluid. On the other hand, Sisson and Whalen (1960) have demonstrated an increase in the blood volumes which they suggest is derived from blood in a storage space such as the liver. However, it does seem certain that a placental transfusion as a result of delay in clamping the cord will be followed by an increase in the blood volume of the baby, and that this increase persists for up to 4 hours (De Marsh, Windle, and Alt, 1942; Usher, Shephard, and Lind, 1963). Some of these writers suggest a possible relation between the various blood volume changes and RDS, but Usher et al. (1963) reported that no abnormality of respiration developed in any of their cases, irrespective of the time of clamping the cord. Steele (1962) has suggested from his studies that the blood volume might best be kept in the low normal range for premature babies, and Taylor, Bright, and Birchard
(1959) showed more abnormal respiratory signs in those babies receiving a placental transfusion.

Our mean figure of $94 \mathrm{ml} . / \mathrm{kg}$. for babies with RDS is not statistically different from the mean of 107 $\mathrm{ml} . / \mathrm{kg}$. for the control series of premature babies. These values are close to those of the full-term normal babies described by Mollison, Veall, and Cutbush (1950), some of whom had received a placental transfusion, and to those of Usher et al. (1963), where cord clamping was delayed. We have, therefore, found no characteristic deviation of the blood volume in RDS. On the other hand, the haematocrit does show a significant deviation.

Most published values for the range of haematocrit in the full-term newborn are in the papers already noted, where the estimation was a necessary part of the technique of blood volume determination. An average normal figure of $50 \%$ is noted for the cord blood. Gairdner et al. (1958) record a rising haematocrit in the first hours of life in 30 of 39 babies, predominantly of average birth weight and without delay in cord clamping. Although exact figures are not given, in a typical case discussed, a change from $53 \%$ to $61 \%$ is noted as being average. The authors suggest a plasma shift into extravascular spaces including the pulmonary alveoli, with a possible contribution to the development of RDS. Usher et al. (1963) have in contrast shown that changes in the haematocrit are dependent on the time of clamping the cord. They noted that 16 cord haematocrits gave an average of $48 \%$ and they use this as the normal for all cases studied. Where the clamping of the cord was delayed, there was an increase in the haematocrit to a mean of $59 \%$ at 30 minutes and $64 \%$ at 4 hours, 
but when the cord was clamped immediately a level of $48 \%$ persisted. Neither group showed any tendency to develop respiratory distress, but none of the babies was below $2.5 \mathrm{~kg}$. birth weight. Babies with a low birth weight were specifically studied by Pincus, Gittleman, Saito, and Sobel (1956), though their samples were of capillary blood. They showed uncorrected haematocrit figures with an average of $58 \%$, and it can be assumed that the venous haematocrit would have been lower. Blanc and Lermontoff (1961) gave figures of over $60 \%$ for babies weighing $1 \cdot 0-2 \cdot 0 \mathrm{~kg}$. and up to 24 hours of age. Our figures for the babies with RDS show a mean value of $48 \%$, which contrasts with most other published results for babies who were not in respiratory distress, and when the difference from the value of $58 \%$ in our normal premature is considered it is found to be statistically significant $(p<0.01)$.

Certain things seem to follow from this observed low figure in the distressed babies. First, if, as De Marsh et al. (1942) and Usher et al. (1963) have each separately indicated, the haematocrit is a function of the volume of the placental red cell transfusion, these babies with a low haematocrit might be inferred to have been deprived of this transfusion and this could be taken to support the thesis that such a transfusion tended to prevent the development of respiratory distress. We know that the majority of these babies did in fact have the cord clamped early. Furthermore, Redmond, Isana, and Ingall (1965) have recently demonstrated that the placental transfusion may be related to the infant's first breaths and initial pulmonary aeration, rather than to the time interval between delivery and clamping of the umbilical cord; and a delay in the onset of respiration is common in infants who subsequently develop RDS. On the other hand the total blood volumes in our cases with RDS fall within the high ranges that Usher et al. (1963) described in their patients with delayed clamping of the cord, and they were not significantly different from the blood volumes of premature infants who did not develop RDS.

Secondly, such low values for the haematocrit in our cases with RDS are certainly not compatible with the sometimes expressed but inadequately investigated belief that babies with RDS have an increased haematocrit. Danks and Stevens (1964) have recently described a baby where polycythaemia caused late respiratory distress which responded well to a 'dextrose exchange transfusion'. They mention that certain groups of babies may carry a particular risk of respiratory distress due to haemoconcentration, but it is clear that in the majority of babies with idiopathic RDS a high haematocrit is not found. Finally, if these babies with RDS have a total blood volume in the range of normal premature babies, as our results seem to indicate, and yet have a low haematocrit and hence a low circulating red cell volume, it is possible that the circulating red cell volume may have diminished during the development of the distressed state or as a consequence thereof. We have no evidence to indicate where the missing red cells have gone. The constant necropsy finding of intense pulmonary congestion, sometimes associated with haemorrhage, might suggest sequestration of the red cells in the lungs, and such an occurrence might explain, in part at least, the respiratory difficulty which these infants experience.

\section{Summary}

The blood volumes and haematocrit values were measured in 17 infants with the idiopathic respiratory distress syndrome and in 20 unaffected infants with a birth weight of less than $2 \cdot 5 \mathrm{~kg}$. Cord clamping was not delayed in these infants.

The mean figure for blood volume in babies with RDS (94 ml./kg.) was not statistically different from the mean of $107 \mathrm{ml} . / \mathrm{kg}$. for the unaffected babies (p $>0 \cdot 1)$. The haematocrit estimations showed a mean of $48 \%$ for babies with RDS and $58 \%$ for the unaffected babies, which is a highly significant difference $(\mathrm{p}<0 \cdot 01)$.

The low values for the haematocrit in our cases of RDS contrast with the sometimes expressed belief that such babies have a high haematocrit. They may indicate sequestration of the red cells in the lungs and this might be related in some degree to the respiratory distress.

Part of the expenses of this study was met by a grant from the Scottish Hospitals Endowments Research Trust.

\section{REFERENCES}

Blanc, W. A., and Lermontoff, T. (1961). Hematocrit values in premature infants. In Dunham's Premature Infants, ed. W. A. Silverman, 3rd ed., p. 542. Hoeber Medical Division, New York. Bonham Carter, R. E., Bound, J. P., and Smellie, J. M. (1956). Mean venous pressures in the first hours of life. Lancet, $2,1320$.

Bound, J. P., Harvey, P. W., and Bagshaw, H. B. (1962). Prevention of pulmonary syndrome of the newborn. ibid., 1, 1200.

Clark, A. C. L., and Gairdner, D. (1960). Postnatal plasma shift in premature infants. Arch. Dis. Childh., 35, 352.

Danks, D. M., and Stevens, L. H. (1964). Neonatal respiratory distress associated with a high haematocrit reading. Lancet, 2, 499.

De Marsh, Q. B., Windle, W. F., and Alt, H. L. (1942). Blood volume of newborn infant in relation to early and late clamping of the umbilical cord. Amer. J. Dis. Child., 63, 1123.

Gairdner, D., Marks, J., Roscoe, J. D., and Brettell, R. O. (1958) The fluid shift from the vascular compartment immediately after birth. Arch. Dis. Childh., 33, 489.

Hutchison, J. H., Kerr, M. M., Douglas, T. A., Inall, J. A., and Crosbie, J. C. (1964). A therapeutic approach in 100 cases of the respiratory distress syndrome of the newborn infant. Pediatrics, 33, 956. 
Mollison, P. L., Veall, N., and Cutbush, M. (1950). Red cell and plasma volume in newborn infants. Arch. Dis. Childh., 25, 242.

Pincus, J. B., Gittleman, I. F., Saito, M., and Sobel, A. E. (1956). A study of plasma values of sodium potassium, chloride, carbon dioxide, carbon dioxide tension, sugar, urea and the protein base binding power $\mathrm{pH}$, and haematocrit in prematures on the first day of life. Pediatrics, 18, 39.

Redmond, A., Isana, S., and Ingall, D. (1965). Relation of onset of respiration to placental transfusion. Lancet, 1, 283.

Sisson, T. R. C., and Whalen, L. E. (1960). The blood volume of infants. III. Alterations in the first hours after birth. J. Pediat., 56, 43.

Steele, M. W. (1962). Plasma volume changes in the neonate. Amer. J. Dis. Child., 103, 10.

Taylor, P. M., Bright, N. H., and Birchard, E. L. (1959). The effect of immediate versus delayed clamping of the umbilical cord on mortality and respiratory rates of the newborn infant. Amer. $J$. Dis. Child., 98, 649.

Usher, R., Shephard, M., and Lind, J. (1963). The blood volume of the newborn infant and placental transfusion. Acta paediat. (Uppsala), 52, 497. 